Acta Crystallographica Section E

Structure Reports

Online

ISSN 1600-5368

S. M. Malathy Sony, ${ }^{\text {a }}$ P. Charles, ${ }^{a}$ M. N. Ponnuswamy ${ }^{\mathrm{a} *}$ and H. S. Yathirajan ${ }^{b}$

${ }^{a}$ Department of Crystallography and Biophysics, University of Madras, Guindy Campus, Chennai 600 025, India, and ${ }^{\mathbf{b}}$ Department of Studies in Chemistry, University of Mysore,

Manasagangotri, Mysore 570 006, India

Correspondence e-mail: mnpsy@hotmail.com

\section{Key indicators}

Single-crystal X-ray study

$T=293 \mathrm{~K}$

Mean $\sigma(\mathrm{C}-\mathrm{C})=0.003 \AA$

$R$ factor $=0.057$

$w R$ factor $=0.199$

Data-to-parameter ratio $=21.6$

For details of how these key indicators were automatically derived from the article, see http://journals.iucr.org/e.

\title{
2,2'-\{(Z)-Ethane-1,2-diylbis[(Z)-o-phenylene- nitrilomethylidyne]\}diphenol (EIEP)
}

The salicylideneaniline moiety in the centrosymmetric title compound, $\mathrm{C}_{28} \mathrm{H}_{24} \mathrm{~N}_{2} \mathrm{O}_{2}$, is a phenol-imine tautomer which is non-planar and photochromic. A strong intramolecular hydrogen-bonding interaction, which is a common feature in related imine-phenol compounds, stabilizes the molecular structure. The $\pi$ system in the salicylideneaniline moiety interacts with symmetry-related $\pi$ systems through face-toface $\pi-\pi$ interactions and $\mathrm{C}-\mathrm{H} \cdots \pi$ interactions, to stabilize the molecules in the crystal structure.

\section{Comment}

Schiff base compounds are often used as ligands in coordination chemistry because of their ability for metal binding and, in particular, salicylaldimines are useful for the synthesis of transition metal complexes (Ligtenbarg et al., 1999). $N$ Substituted salicylaldimines are of interest because of their thermochromism and photochromism in the solid state, which may involve reversible proton transfer from the hydroxyl $\mathrm{O}$ atom to the imine $\mathrm{N}$ atom (Moustakali-Mavridis et al., 1978; Hadjoudis et al., 1987; Xu et al., 1994); charge transport occurs through intermolecular overlap of $\pi$ orbitals. Of the two tautomers, one a phenol-imine structure and the other a quinoid structure, most crystal structures concern phenolimine tautomers (Ligtenbarg et al., 1999). It has been proposed that Schiff base molecules exhibiting thermochromism are planar, while those exhibiting photochromism are non-planar (Moustakali-Mavridis et al., 1978).

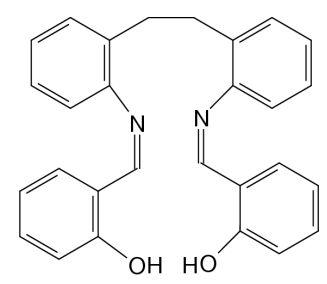

(I)

The title compound, (I) (Fig. 1), has two salicylideneaniline moieties linked by an ethylene bridge. Only one half of the molecule constitutes the asymmetric unit and the other half is centrosymmetrically related. The crystal structure shows that the salicylideneaniline moiety is the phenol-imine tautomer with the $\mathrm{H}$ atom bound to $\mathrm{O} 16$.

The bond distances observed for the compound do not deviate significantly from the mean values for similar phenolimine tautomeric structures (Ligtenbarg et al., 1999; Elmali \& Elerman, 1997; Elerman et al., 1991, 1992, 1994, 1995; Elmali et al., 1995; Kevran et al., 1996); in particular, C9-C10 = $1.445 \AA, \mathrm{C} 11-\mathrm{O} 16=1.349 \AA$ and $\mathrm{C} 9-\mathrm{N} 8=1.287 \AA$. The
Received 10 May 2004 Accepted 18 May 2004 Online 29 May 2004 


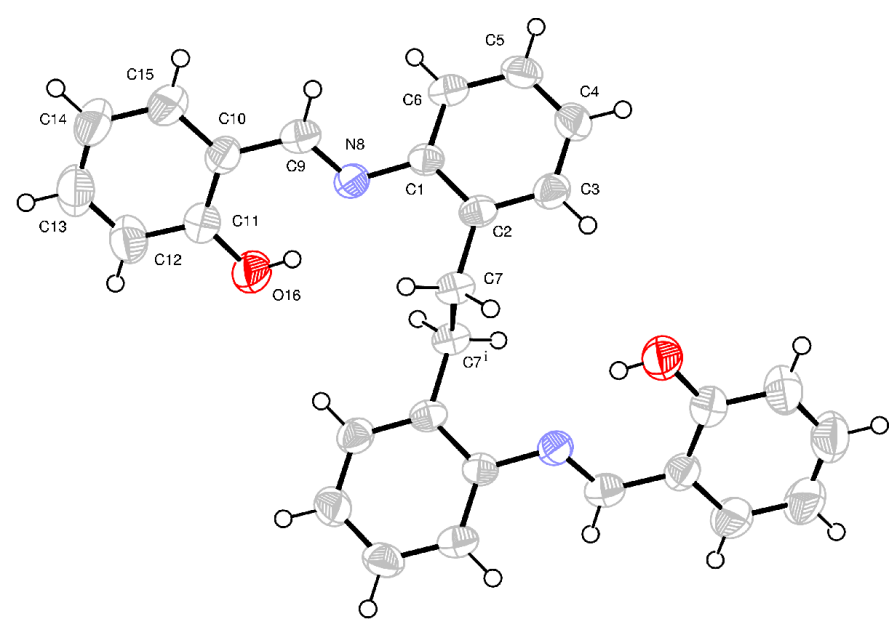

Figure 1

ORTEP-3 (Farrugia, 1997) plot of the title compound, showing 30\% probability displacement ellipsoids and the atom-numbering scheme. [Symmetry code: (i) $2-x,-y,-z$.]

salicylideneaniline moiety exhibits a trans-planar configuration of the central backbone $\left[\mathrm{C} 1-\mathrm{N} 8-\mathrm{C} 9-\mathrm{C} 10=179.4(2)^{\circ}\right]$.

The salicylideneaniline moiety is non-planar and photochromic (Bernstein, 1967); moieties $A$ (atoms N8/C1-C6) and $B(\mathrm{O} 16 / \mathrm{C} 9-\mathrm{C} 15)$ are inclined at an angle of $43.9(1)^{\circ}$, reflecting mainly the twist about the $\mathrm{N} 8-\mathrm{C} 9$ bond $[\mathrm{C} 9-\mathrm{N} 8-$ $\left.\mathrm{C} 1-\mathrm{C} 6=42.4(3)^{\circ}\right]$. Clearly this conformation is not suitable for direct coordination to a metal ion (Elmali \& Elerman, 1997).

A strong intramolecular hydrogen-bonding interaction between the imine $\mathrm{N}$ atom (N8) and the phenolic $\mathrm{H}$ atom (on O16) forms a pseudo-six-membered ring, a feature common in related imine-phenol compounds (Bhattacharyya et al., 1998). The geometry of this intramolecular interaction $[\mathrm{H} 16 \cdots \mathrm{N} 18=$ $1.90 \AA, \mathrm{O} 16 \cdots \mathrm{N} 8=2.616$ (2) $\AA$ and $\left.\mathrm{O} 16-\mathrm{H} 16 \cdots \mathrm{N} 8=146^{\circ}\right]$ is comparable to those observed for similar types of compounds (Elmali \& Elerman, 1997; Elerman et al., 1994, 1995; Xu et al., 1994).

The phenol $\pi$ system (C10-C15) of the salicylideneaniline moiety interacts with its own symmetry-related $\pi$ system at $(1-x,-y,-z)$ in a face-to-face manner, the centroid $(C g)-$ centroid distance being 3.841 (2) $\AA$ and the angle $(\alpha)$ between their normals being $0.02^{\circ}$. The benzene ring (C1-C6) also

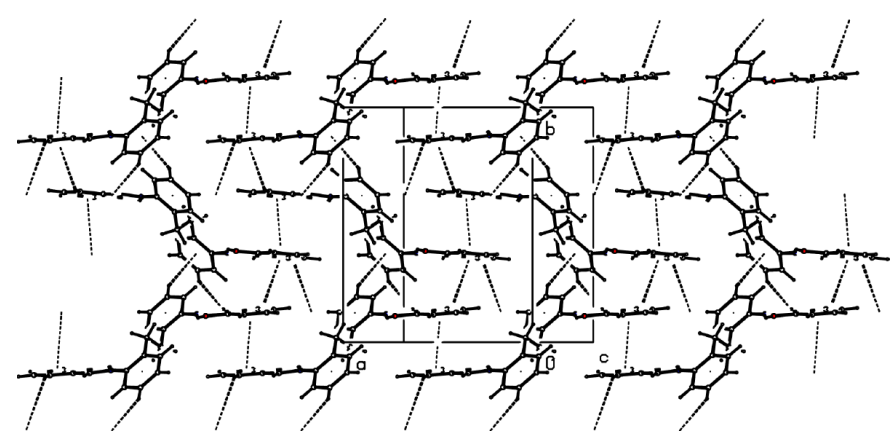

Figure 2

Packing diagram of the molecules, viewed down the $c$ axis, showing the $\pi$ $\pi$ and $\mathrm{C}-\mathrm{H} \cdots \pi$ interaction network (dashed lines). weakly interacts with its symmetry-related $\pi$ system at $(2-x$, $-y, 1-z)\left[C g \cdots C g=4.097\right.$ (2) $\AA$ and $\left.\alpha=0.03^{\circ}\right]$. These interactions link the molecules into layers parallel to the $a c$ plane. Atoms C5 and C15 interact with the benzene and phenol $\pi$ system, respectively, of a symmetry-related molecule through $\mathrm{C}-\mathrm{H} \cdots \pi$ interactions $[\mathrm{H} 5 \cdots \mathrm{Cg} 1=2.75 \AA$, $\mathrm{C} 5 \cdots \mathrm{Cg} 1$ $=3.569$ (3) $\AA$ and $\mathrm{C} 5-\mathrm{H} 5 \cdots C g 1=147^{\circ} ; \mathrm{H} 15 \cdots C g 2=3.33 \AA$, $\mathrm{C} 15 \cdots C g 2=3.812(3) \AA$ and $\mathrm{C} 15-\mathrm{H} 15 \cdots C g 2=115^{\circ}$; where $C g 1$ and $C g 2$ denote the centroids of rings $\mathrm{C} 1-\mathrm{C} 6$ and $\mathrm{C} 10$ $\mathrm{C} 15$ of the molecule at $\left.\left(x, \frac{1}{2}-y, \frac{1}{2}+z\right)\right]$. These interactions link adjacent layers into a three-dimensional network (Fig. 2).

\section{Experimental}

$4,4^{\prime}$-Ethylenedianiline or 4,4'-diaminodibenzyl ( $\left.1 \mathrm{~mol}, 2.12 \mathrm{~g}\right)$ in ethanol was mixed with salicyladehyde ( $2 \mathrm{~mol}, 2.44 \mathrm{~g})$ in ethanol with vigorous stirring at room temperature $(303 \mathrm{~K})$. The resulting precipitate was washed with a minimum quantity of ethanol and the product was recrystallized from chloroform to give a $90 \%$ yield of the title Schiff base.

\section{Crystal data}

\section{$\mathrm{C}_{28} \mathrm{H}_{24} \mathrm{~N}_{2} \mathrm{O}_{2}$}

$M_{r}=420.49$

Monoclinic, $P 2_{1} / c$

$a=11.817(3) \AA$

$b=13.762(6) \AA$

$c=6.873(2) \AA$

$\beta=101.15(3)^{\circ}$

$V=1096.6(6) \AA^{3}$

$Z=2$

\section{Data collection}

Enraf-Nonius CAD-4 diffractometer

Non-profiled $\omega / 2 \theta$ scans

Absorption correction: none

3425 measured reflections

3179 independent reflections

1504 reflections with $I>2 \sigma(I)$

$R_{\text {int }}=0.042$

\section{Refinement}

Refinement on $F^{2}$

$R\left[F^{2}>2 \sigma\left(F^{2}\right)\right]=0.057$

$w R\left(F^{2}\right)=0.199$

$S=1.01$

3179 reflections

147 parameters

$\mathrm{H}$-atom parameters constrained

$$
\begin{aligned}
& D_{x}=1.273 \mathrm{Mg} \mathrm{m}^{-3} \\
& \text { Mo } K \alpha \text { radiation } \\
& \text { Cell parameters from } 25 \\
& \text { reflections } \\
& \theta=8-15^{\circ} \\
& \mu=0.08 \mathrm{~mm}^{-1} \\
& T=293 \text { (2) K } \\
& \text { Block, yellow } \\
& 0.25 \times 0.22 \times 0.20 \mathrm{~mm}
\end{aligned}
$$

$$
\begin{aligned}
& \theta_{\max }=30.0^{\circ} \\
& h=-16 \rightarrow 16 \\
& k=0 \rightarrow 19 \\
& l=0 \rightarrow 9 \\
& 3 \text { standard reflections } \\
& \quad \text { frequency: } 120 \text { min } \\
& \quad \text { intensity decay: none }
\end{aligned}
$$

$$
\begin{aligned}
& w=1 /\left[\sigma^{2}\left(F_{o}^{2}\right)+(0.0961 P)^{2}\right. \\
& +0.0403 P] \\
& \text { where } P=\left(F_{o}^{2}+2 F_{c}^{2}\right) / 3 \\
& (\Delta / \sigma)_{\max }=0.005 \\
& \Delta \rho_{\max }=0.19 \mathrm{e}^{-3} \\
& \Delta \rho_{\min }=-0.17 \mathrm{e} \AA^{-3} \\
& \text { Extinction correction: SHELXL97 } \\
& \text { Extinction coefficient: } 0.039 \text { (7) }
\end{aligned}
$$

$\mathrm{H}$ atoms were positioned geometrically $(\mathrm{O}-\mathrm{H}=0.82 \AA$ and $\mathrm{C}-\mathrm{H}$ $=0.93 \AA$ ) and allowed to ride on their parent atoms, with $U_{\text {iso }}(\mathrm{H})$ values set at $1.5 U_{\text {eq }}(\mathrm{O})$ for the hydroxyl $\mathrm{H}$ atom and at $1.2 U_{\text {eq }}(\mathrm{C})$ for the other $\mathrm{H}$ atoms.

Data collection: CAD-4 EXPRESS (Enraf-Nonius, 1994); cell refinement: CAD-4 EXPRESS; data reduction: XCAD4 (Harms \& Wocadlo, 1995); program(s) used to solve structure: SHELXS97 (Sheldrick, 1997); program(s) used to refine structure: SHELXL97 (Sheldrick, 1997); molecular graphics: PLATON (Spek, 2003) and ORTEP-3 (Farrugia, 1997); software used to prepare material for publication: PLATON.

SMMS acknowledges the Council of Scientific and Industrial Research for financial support. 


\section{References}

Bernstein, J. L. (1967). Acta Cryst. 22, 747-748.

Bhattacharyya, P., Parr, J. \& Slawin, A. M. Z. (1998). J. Chem. Soc. Dalton Trans. pp. 3609-3614.

Elerman, Y., Elmali, A., Kabak, M., Aydin, M. \& Peder, M. (1994). J. Chem. Crystallogr. 24, 603-606.

Elerman, Y., Elmali, A. \& Svoboda, I. (1995). Acta Cryst. C51, 23442346.

Elerman, Y., Paulus, H., Svoboda, I. \& Fuess, H. (1992). Z. Kristallogr. 198 $135-136$.

Elerman, Y., Svoboda, I. \& Fuess, H. (1991). Z. Kristallogr. 196, 309-311.

Elmali, A. \& Elerman, Y. (1997). Acta Cryst. C53, 791-793.

Elmali, A., Ozbey, S., Kendi, E., Kabak, M. \& Elerman, Y. (1995). Acta Cryst. C51, 1878-1880.
Enraf-Nonius (1994). CAD-4 EXPRESS. Enraf-Nonius, Delft, The Netherlands.

Farrugia, L. J. (1997). J. Appl. Cryst. 30, 565.

Hadjoudis, E., Vitterakis, M. \& Mavridis, I. M. (1987). Tetrahedron, 43, 13451360.

Harms, K. \& Wocadlo, S. (1995). XCAD4. University of Marburg, Germany. Kevran, S., Elmali, A. \& Elerman, Y. (1996). Acta Cryst. C52, 3256-3258.

Ligtenbarg, A. G. J., Hage, R., Meetsma, A. \& Feringa, B. L. (1999). J. Chem. Soc. Perkin Trans. 2, pp. 807-812.

Moustakali-Mavridis, I., Hadjoudis, E. \& Mavridis, A. (1978). Acta Cryst. B34, 3709-3715.

Sheldrick, G. M. (1997). SHELXS97 and SHELXL97. University of Göttingen, Germany.

Spek, A. L. (2003). J. Appl. Cryst. 36, 7-13.

Xu, X.-X., You, X.-Z., Sun, Z.-F., Wang, X. \& Liu, H.-X. (1994). Acta Cryst. C50, 1169-1171. 